\title{
Review of Network Economics
}

$\begin{array}{lll}\text { Volume 9, Issue } 3 & 2010 & \text { Article } 5\end{array}$

\section{Optimal Price Allocations in Two-Sided Markets}

\author{
Dennis L. Weisman, Kansas State University
}

\section{Recommended Citation:}

Weisman, Dennis L. (2010) "Optimal Price Allocations in Two-Sided Markets," Review of Network Economics: Vol. 9: Iss. 3, Article 5.

DOI: $10.2202 / 1446-9022.1220$ 


\title{
Optimal Price Allocations in Two-Sided Markets
}

\author{
Dennis L. Weisman
}

\begin{abstract}
This paper derives an optimal allocation rule $\left(\alpha^{*}\right)$ that (i) assigns a share of the transaction price to the buyer-side of the two-sided market; (ii) is equivalent to the Rochet-Tirole price structure rule; and (iii) is a function of the own/cross-price elasticities. For linear demands, demand symmetry is sufficient for $\alpha^{*}=1 / 2$ and $\alpha^{*}$ is decreasing (increasing) in the own-price (cross-price) sensitivity parameter of buyer-side demand.
\end{abstract}

KEYWORDS: two-sided markets, price allocations

Author Notes: I am grateful to the editor, Julian Wright, and an anonymous referee for very constructive comments on an earlier draft of this manuscript. The usual caveat applies. 
Weisman: Optimal Price Allocations in Two-Sided Markets

\section{Introduction}

Over the past decade, a growing literature has emerged on two-sided markets. A two-sided market is a market in which one side of the market requires the participation of the other side of the market in order for there to be a viable enterprise-the proverbial "chicken and egg problem." The platform provider solves this problem by using prices as instruments to bring both sides of the market on board. Examples include auctions, credit cards, dating bars, newspapers, video consoles and Yellow Pages (Rysman, 2009, Wright, 2004a).

Broadband markets constitute another prominent example of a two-sided market in which the broadband provider serves as the intermediary connecting content providers with individual subscribers. In the United States, the Federal Communications Commission is currently deciding upon its role in regulating broadband markets under the rubric of net neutrality, including possible constraints on the structure of broadband pricing (FCC, 2009). For example, should regulators prohibit broadband providers from charging content providers, the so-called zero-price mandate, ${ }^{1}$ or from engaging in price discrimination?

The platform provider in a two-sided market faces two different pricing decisions - the level of the transaction price and the structure of the transaction price. The structure of the transaction price is simply an allocation of the transaction price between the buyer side and the seller side of the market so as to maximize the volume of usage. Modeling the price structure rule as an optimal allocation problem may serve to clarify some confusion in the literature regarding its economic interpretation.

An understanding of the structure of pricing in two-sided markets is also important from an antitrust perspective. All too often antitrust authorities apply one-sided logic to two-sided markets. That is to say, antitrust authorities tend to focus on the total transaction price or the price on only one-side of the market, the buyer-side, for example, without due consideration of the interplay between the two sides of the market. The EU Commission's recent examination of the multilateral interexchange fees assessed by MasterCard and Visa are two prominent examples (European Commission, 2008, 2009).

The primary objectives of this article are three-fold. First, we demonstrate that the Rochet-Tirole price structure rule is equivalent to an optimal allocation rule that assigns an optimal share $\left(\alpha^{*}\right)$ of the transaction price to the buyer-side of the two-sided market. Second, we show that $\alpha^{*}$ is a function of the underlying own-price and cross-price elasticities. Third, we develop comparative statics for $\alpha^{*}$ based on linear demand functions.

\footnotetext{
${ }^{1}$ See Hemphill (2008) for a comprehensive examination of the zero-price mandate in broadband markets. Whether innovation on the Internet is enhanced or diminished by a zero-price mandate remains an open question.
} 
The key findings of this analysis based on linear demand functions are as follows: (i) demand symmetry is sufficient for $\alpha^{*}=1 / 2$; (ii) $\alpha^{*}<1 / 2$ for independent demands when buyer-side demand is more price-sensitive than seller-side demand; (iii) $\alpha^{*}$ is decreasing in the buyer-side own-price sensitivity parameter, ceteris paribus; and (iv) $\alpha^{*}$ is increasing in the buyer-side cross-price sensitivity parameter, ceteris paribus.

\section{Optimal Price Allocations}

Let the transaction price level be given by $p=p^{B}+p^{S}$, where $p^{B}$ is the transaction price to the buyer and $p^{S}$ is the transaction price to the seller. The price structure is determined by the allocation of $p$ between $p^{B}=\alpha p$ and $p^{S}=(1-\alpha) p$, where $\alpha \in[0,1] .^{2}$

Let $n^{B}\left(p^{B}, p^{S}\right)$ and $n^{S}\left(p^{S}, p^{B}\right)$ denote the number of buyers and sellers, respectively, and let $c$ denote the marginal cost of the transaction. The profit for the platform provider is given by

(1) $\pi=n^{B}\left(p^{B}, p^{S}\right) n^{S}\left(p^{B}, p^{S}\right)\left(p^{B}+p^{S}-c\right){ }^{3}$

Following Rochet and Tirole (2006) and Schmalensee (2002), for a given $p$, the optimal price structure is obtained by maximizing the volume of usage $(V)$, or

$V(p)=\max \left\{n^{B}\left(p^{B}, p^{S}\right) n^{S}\left(p^{B}, p^{S}\right)\right.$ under the constraint that $\left.p^{B}+p^{S}=p\right\} .^{4}$

Let the own-price elasticities be denoted by $\eta^{B}=-\frac{\partial n^{B}}{\partial p^{B}} \frac{p^{B}}{n^{B}}$ and $\eta^{S}=$ $-\frac{\partial n^{S}}{\partial p^{S}} \frac{p^{S}}{n^{S}}$, and the cross-price elasticities by $\eta^{B S}=\frac{\partial n^{B}}{\partial p^{S}} \frac{p^{S}}{n^{B}}$ and $\eta^{S B}=\frac{\partial n^{S}}{\partial p^{B}} \frac{p^{B}}{n^{S}}$.

The platform provider's problem for finding the optimal allocation rule, $\alpha^{*}$, is given by

(2) $\alpha^{*}=\operatorname{argmax} \pi(\alpha \mid p)=n^{B}\left(p^{B}, p^{S}\right) n^{S}\left(p^{B}, p^{S}\right)(p-c)$.

Provided that (2) is concave in $\alpha$, the first-order condition is both necessary and sufficient for a maximum and yields an optimal allocation rule that is a function of the own-price and cross-price elasticities.

${ }^{2}$ In certain cases, one side of the market may be "bribed" to participate in which case $\alpha^{*}$ is not bounded on $[0,1]$.

3 The price level is determined by a standard "Lerner Index" expression, or $\frac{p-c}{p}=\frac{1}{\eta}$, where $\eta=-\frac{p V^{\prime}(p)}{V(p)}$ is the elasticity of volume with respect to total price.

${ }^{4}$ Notably, whether the market is one-sided (two-sided) turns on whether $\left.\frac{\partial V}{\partial \alpha}\right|_{d p=0}=(\neq) 0$.

DOI: $10.2202 / 1446-9022.1220$ 
Proposition 1. The optimal allocation rule for the transaction price is given by

(3) $\alpha^{*}=\frac{\eta^{B}-\eta^{S B}}{\eta^{B}-\eta^{S B}+\eta^{S}-\eta^{B S}}$.

For independent demands, ${ }^{5} \eta^{B S}=\eta^{S B}=0$ and the optimal allocation rule in (4) implies that

(4) $\alpha^{*}=\frac{\eta^{B}}{\eta^{B}+\eta^{S}} \Rightarrow \frac{p B}{p B+p S}=\frac{\eta^{B}}{\eta^{B}+\eta^{S}} \Rightarrow 1+\frac{p S}{p B}=1+\frac{\eta^{S}}{\eta^{B}} \Rightarrow\left\{\frac{p B}{\eta^{B}}=\frac{p S}{\eta^{S}}\right\}$.

The expression in braces in (4) is the familiar price structure rule of Rochet and Tirole (2003).

Proposition 2. In the case of independent demands, the optimal allocation rule in (4) is equivalent to the Rochet-Tirole price structure rule: $\frac{p B}{\eta^{B}}=\frac{p S}{\eta^{S}}$.

The Rochet-Tirole price structure rule has given rise to some confusion in the literature because it appears to suggest that the allocation of the transaction price is increasing as opposed to decreasing with the own-price elasticity of demand, contrary to intuition. ${ }^{6}$ Krueger (2009) provides clarification of this issue by recognizing that the price structure rule holds only in equilibrium and that each of the elasticities is itself a function of the particular price level. This article builds on these important insights by deriving the relevant comparative statics and formally characterizing the demand conditions under which it is optimal to deviate from a symmetric allocation of the price burden in the case of independent and interdependent linear demands.

\section{Linear Demands}

\subsection{Independent Demands}

Let the linear demand functions for the buyer and seller side of the market be given, respectively, by

(5) $n^{B}=a_{B}-d_{B} p^{B}$

\footnotetext{
${ }^{5}$ Independent demands refer to demands that are independent across the two sides of the market. This is a standard assumption in the two-sided markets literature. See, for example, Rochet and Tirole (2003) and Schmalensee (2002).

${ }^{6}$ See Krueger (2009) and the references cited therein.
} 
(6) $n^{S}=a_{S}-d_{S} p^{S}$,

where all parameters are positive with $n^{B}>0$ and $n^{S}>0 \forall \alpha \in[0,1]$.

Proposition 3. When demands are linear and given by (5) and (6), the optimal (efficient) allocation rule is given by

(7) $\alpha^{*}=\frac{d_{B} d_{S} p-d_{B} a_{S}+d_{S} a_{B}}{2 d_{B} d_{S} p}=\frac{1}{2}-\frac{k}{2 d_{B} d_{S} p},{ }^{7}$

where $k=\left[d_{B} a_{S}-d_{S} a_{B}\right]$ is independent of $p$.

The proof is immediate upon substituting (5) and (6) into (2) and recognizing that the resulting profit function is concave in $\alpha$. It is straightforward, albeit somewhat tedious, to show that (7) and (4) are equivalent.

It is noteworthy that $\alpha^{*}$ falls below $1 / 2$ in (7) when $k>0 \Rightarrow d_{B} a_{S}>d_{S} a_{B}$, or $d_{B}>d_{S}\left(\frac{a_{B}}{a_{S}}\right)$. Hence, when $a_{B}=a_{S}$, the buyer side of the market bears a smaller burden of the transaction price when $d_{B}>d_{S}$, or when the own-price sensitivity parameter for the buyer side of the market is greater than the own-price sensitivity parameter for the seller side of the market. This result accords with economic intuition in that there is an inverse relationship between the allocation of the price burden and the own-price sensitivity parameter, ceteris paribus.

Two corollaries follow directly from Proposition 3.

Corollary 1. For symmetric linear demands (or more generally when $a_{S} / d_{S}=$ $\left.a_{B} / d_{B}\right),{ }^{8} \alpha^{*}=1 / 2$.

Corollary 2. (i) $\frac{\partial \alpha^{*}}{\partial d_{B}}=-\frac{a_{B}}{2\left(d_{B}\right)^{2} p}<0$ and (ii) $\frac{\partial \alpha^{*}}{\partial d_{S}}=\frac{a_{S}}{2\left(d_{S}\right)^{2} p}>0$.

Corollary 1 establishes that symmetry of demands is sufficient for an optimal allocation of $\alpha^{*}=1 / 2$ that divides the transaction price equally across the two sides of the market.

Corollary 2 indicates that as demand becomes more price-sensitive on one side of the market, it is efficient to decrease the allocation of the transaction price

\footnotetext{
${ }^{7}$ We can refer to $\alpha^{*}$ as the efficient allocation rule here because, at least for linear, independent demands, the monopolist's rule for allocating the transaction price across the two sides of the market is also efficient. See Rochet and Tirole (2003, p. 29). Moreover, as Weyl (2009a, p. 6) observes, "The price balance chosen by the monopolist may well be optimal and when it is not it may be difficult to determine which direction it would be beneficial for it to move." See also Weyl (2009b).

${ }^{8}$ This expression represents an equality of reservation prices. I am grateful to an anonymous referee for this observation.
}

DOI: $10.2202 / 1446-9022.1220$ 
Weisman: Optimal Price Allocations in Two-Sided Markets

on that side of the market. This is a variation on the seesaw principle of pricing in two-sided markets. To wit, a higher price on one side of the market is commonly associated with a lower price on the other side of the market (Rochet and Tirole, 2006). This result is of potential interest to antitrust authorities because there may be a tendency to focus on an increase in price on one side of the market without due consideration of a countervailing decrease in price on the other side of the market.

\subsection{Interdependent Demands}

Let the linear interdependent demand functions for the buyer and seller side of the market be given, respectively, by

(8) $n^{B}=a_{B}-d_{B} p^{B}-f_{B} p^{S}$

(9) $n^{S}=a_{S}-d_{S} p^{S}-f_{S} p^{B}$,

where all parameters are positive with $n^{B}>0$ and $n^{S}>0 \forall \alpha \in[0,1]$. Hence, there is a complementary demand relationship between the two sides of the market. ${ }^{9}$

Assumption 1. Own-price effects dominate cross-price effects: $d_{B}>f_{B}$ and $d_{S}>f_{S}$.

Proposition 4. When demands are linear and given by (8) and (9), the optimal allocation rule is given by

(10) $\alpha^{*}=\frac{\left[\left(d_{S}-f_{S}\right)\left(a_{B}-f_{B} p\right)-\left(d_{B}-f_{B}\right)\left(a_{S}-d_{S} p\right)\right]}{2\left[\left(d_{B}-f_{B}\right)\left(d_{S}-f_{S}\right)\right] p}=\frac{1}{2}-\frac{k(p)}{2\left[\left(d_{B}-f_{B}\right)\left(d_{S}-f_{S}\right)\right] p}$,

where $k(p)=\left[\left(d_{B}-f_{B}\right) a_{S}-\left(d_{S}-f_{S}\right) a_{B}+\left(d_{S} f_{B}-d_{B} f_{S}\right) p\right] .{ }^{10}$ The proof is immediate upon substituting (8) and (9) into (2) and recognizing that the resulting profit function is concave in $\alpha$ under Assumption 1. It is straightforward, albeit

${ }^{9}$ An example of interdependent demands is the credit-card models of Rochet and Tirole (2002) and Wright (2004) where competing merchants accept cards for strategic reasons. In the creditcard framework, the merchants' quasi-demand, $n^{S}$, depends on both the cardholder fee and the merchant fee. I am grateful to Julian Wright for this example. See Chakravorti (2010) for a survey of the payment cards literature.

${ }^{10}$ Note that $k(p)$ is a function of the transaction price in the case of interdependent linear demands, but is invariant to the transaction price in the case of independent linear demands. This difference derives from the fact that, in the case of interdependent demands, changes in the price allocation serve to shift the respective demand curves. 
somewhat tedious, to show that (10) is equivalent to (3). In addition, note that when the cross effects are identically zero, $f_{B}=f_{S}=0$ and (10) reduces to (7).

In order to develop the intuition for $k(p)$ and relate it to the case of independent demands, it is instructive to rewrite the expression as $k(p)=$ $k^{r}(p)-k^{r / t}(p)$, where

(11) $k^{r}(p)=\left(d_{B} a_{S}-d_{S} a_{B}\right)-\left(d_{B} f_{S} P^{B}-d_{S} f_{B} P^{S}\right)$, and

(12) $k^{r / t}(p)=\left(f_{B} a_{S}-f_{S} a_{B}\right)-\left(d_{S} f_{B} P^{B}-d_{B} f_{S} P^{S}\right)$.

$k^{r}(p)$ is the equation for the equality of reservation prices and $k^{r / t}(p)$ is its "transpose" obtained by interchanging $d$ and $f$. In addition, the term in the first set of parentheses on the right-hand side of (11) is the expression for $k$ when demands are independent.

As in the independent demands case, symmetry of demands is sufficient for the optimal allocation of $\alpha^{*}=1 / 2$ that divides the transaction price equally across the two sides of the market.

Corollary 3. For symmetric linear demands, $a_{B}=a_{S}, d_{B}=d_{S}, f_{B}=f_{S}$ and $\alpha^{*}=$ $1 / 2$.

Corollary 4. (i) $\frac{\partial \alpha^{*}}{\partial d_{B}}=-\frac{\left[\left(a_{B}-f_{B} p\right)\right]}{2 p\left(d_{B}-f_{B}\right)^{2}}<0$ and (ii) $\frac{\partial \alpha^{*}}{\partial d_{S}}=\frac{\left[\left(a_{S}-f_{S} p\right)\right]}{2 p\left(d_{S}-f_{S}\right)^{2}}>0 .{ }^{11}$

The economic intuition underlying Corollary 4 is the same as that for Corollary 2. A small increase in the own-price sensitivity parameter on one side of the market increases the allocation of the price burden on the other side of the market, ceteris paribus.

Corollary 5. (i) $\frac{\partial \alpha^{*}}{\partial f_{B}}=\frac{\left[\left(a_{B}-d_{B} p\right)\right]}{2 p\left(d_{B}-f_{B}\right)^{2}}>0$ and (ii) $\frac{\partial \alpha^{*}}{\partial f_{S}}=-\frac{\left[\left(a_{S}-d_{S} p\right)\right]}{2 p\left(d_{S}-f_{S}\right)^{2}}<0.12$

Corollary 5 provides the comparative statics for the cross-price sensitivity parameters. A small increase in the cross-price sensitivity parameter shifts the optimal allocation of the price burden in the opposite direction as that for a small increase in the own-price sensitivity parameter, ceteris paribus. Formally,

\footnotetext{
${ }^{11}$ That the numerator is negative in (i) and positive in (ii) follows directly from Assumption 1. For example, in the numerator of (i), $a_{B}-f_{B} p>0$ since $a_{B}-f_{B} p=a_{B}-f_{B} p^{B}-f_{B} p^{S}>a_{B}-$ $d_{B} p^{B}-f_{B} p^{S}=n^{B}>0$ since $d_{B}>f_{B}$.

${ }^{12}$ That the numerator is positive in (i) and negative in (ii) follows directly from the assumption that $n^{B}>0$ and $n^{S}>0 \forall \alpha \in[0,1]$.
}

DOI: $10.2202 / 1446-9022.1220$ 
Weisman: Optimal Price Allocations in Two-Sided Markets

$\operatorname{sgn}\left\{\frac{\partial \alpha^{*}}{\partial d_{B}}\right\}=-\operatorname{sgn}\left\{\frac{\partial \alpha^{*}}{\partial f_{B}}\right\}$ and $\operatorname{sgn}\left\{\frac{\partial \alpha^{*}}{\partial d_{S}}\right\}=-\operatorname{sgn}\left\{\frac{\partial \alpha^{*}}{\partial f_{S}}\right\}$. The effect of an increase in the own-price (cross-price) sensitivity parameter is to increase (decrease) the price burden on the other side of the market. It follows that the effect of a small increase in either the own-price or cross-price sensitivity parameter is to decrease the price associated with that parameter.

\section{Conclusion}

This article derives an optimal allocation rule ( $\left.\alpha^{*}\right)$ that (i) assigns a share of the price burden to the buyer-side of the market; (ii) is equivalent to the RochetTirole price structure rule for two-sided markets; and (iii) is a function of the underlying own/cross-price elasticities. The comparative static results for linear demands are consistent with economic intuition-symmetry of demands is sufficient for $\alpha^{*}=1 / 2$ and $\alpha^{*}$ is decreasing (increasing) in the own-price (crossprice) sensitivity parameter of buyer-side demand, ceteris paribus.

\section{References}

Chakravorti, Sujit. (2010) "Externalities in Payment Card Networks: Theory and Evidence,” Review of Network Economics, 9: 1-26.

European Commission. (2009) “Antitrust: Commissioner Kroes notes MasterCard's decision to cut cross-border Multilateral Interchange Fees (MIFs) and to repeal recent scheme fee increases-frequently asked questions.” MEMO/09/143, Brussels (April 1).

European Commission. (2008) "Antitrust: Commission initiates formal proceedings against Visa Europe Limited.” MEMO/08/170, Brussels (March 26).

Federal Communications Commission, (2009) Notice of Proposed Rulemaking, In the Matter of Preserving the Open Internet/Broadband Industry Practices, GN Docket No. 09-191/WC Docket No. 07-52, (October 22).

Hemphill, Scott, C. (2008) "Network Neutrality and the False Promise of ZeroPrice Regulation.” Yale Journal on Regulation, 25: 135-179.

Krueger, Malte. (2009) "The Elasticity Rule for Two-Sided Markets: A Note.” Review of Network Economics, 8: 271-278. 
Rochet, Jean-Charles and Jean Tirole. (2002) "Cooperation Among Competitors: Some Economics of Payment Card Associations.” Rand Journal of Economics, 33: 549-570.

Rochet, Jean-Charles and Jean Tirole. (2003) "Platform Competition in TwoSided Markets." Journal of the European Economic Association, 1: 9901029.

Rochet, Jean-Charles and Jean Tirole. (2006) "Two-Sided Markets: A Progress Report.” Rand Journal of Economics, 37: 645-667.

Rysman, Marc. (2009) “The Economics of Two-Sided Markets.” Journal of Economic Perspectives, 23: 124-143.

Schmalensee, Richard. (2002) "Payment Systems and Interchange Fees." The Journal of Industrial Economics, 50: 103-122.

Weyl, Glen E. (2009a) “The Price Theory of Two-Sided Markets.” (March) (available at http://papers.ssrn.com/sol3/papers.cfm?abstract_id=1324317).

Weyl, Glen E. (2009b) “A Price Theory of Multi-Sided Platforms.” The American Economic Review, (October) forthcoming. (available at http://papers.ssrn.com/sol3/papers.cfm?abstract_id=1324415).

Wright, Julian. (2004a) "One-Sided Logic in Two-Sided Markets." Review of Network Economics, 3: 44-64.

Wright, Julian. (2004b) "Determinants of Optimal Interchange Fees in Credit Payment Systems.” Journal of Industrial Economics, 52: 1-26. 